\title{
Kamu Ar-Ge Merkezi Çalışanlarının Çatışma Nedenleri ve İşlevsel Çatışma Yönetimi Becerileriyle İlgili Görüşleri ${ }^{1}$
}

\author{
Hasan KARABAKKAL ${ }^{2 *}$, Alev TORUN ${ }^{3}$
}

Geliş Tarihi/Received: 14.10.2019

Kabul Tarihi/Accepted: 26.11.2019

Araştırma Makalesi/Research Article

\section{ÖZET}

$\mathrm{Bu}$ araştırma, kamuya bağlı araştırma ve geliştirme merkezlerinde çatışmanın nedenleri ile işlevsel çatışma yönetimi becerilerinin anlaşılmasına katkı sunmayı hedefleyen keşifsel bir çalışmadır. Çalışmanın başında yarı yapılandırılmış mülakat formlarıyla araştırma evrenine mensup 14 çalışan, 4 proje yürütücüsü, 3 profesyonel eğitici ve 2 akademisyen ile görüşmeler yapılmıştır. Elde edilen nitel veriler MAXQDA 2018. 02 programı ile analiz edilmiş, bulgular 1şığında nicel veri toplama aracı geliştirilmiş ve kolaylıkla erişilebilen örnekleme yöntemi ile 133 kişilik örneklemden (46 kadın, 87 erkek Ar-Ge personeli) çatışmaya yol açan etkenler ve başarılı çatışma yönetimi becerileri hakkında nicel veri toplanmıştır. Veriler, SSPS 22 programı yardımı ile tanımlayıcı analiz yöntemi kullanılarak analiz edilmiş ve bulgular çalışanların öğrenme ve gelişim ihtiyaçları çerçevesinde tartışılmıştır.

Anahtar Kelimeler: Çatışma Nedenleri, İşlevsel Çatışma Yönetimi Becerileri, Ar-Ge Kurumları, Öğrenme ve Gelişim İhtiyaçları

\footnotetext{
1 Bu çalışma, Marmara Üniversitesi Sosyal Bilimler Enstitüsü'nde Prof. Dr. Alev TORUN danışmanlığında yürütülen "İşlevsel Çatışma Yönetim Kapasitesinin Arttırılması: Ar-Ge Çalışanları için Özelleştirilmiş Müdahale Programının Rolü” başlıklı doktora tezinden üretilmiştir.

2 Öğrenci, Marmara Üniversitesi, İşletme Fakültesi, Örgütsel Davranış Bölümü

* Sorumlu yazar/Corresponding author

E-mail/e-ileti: hasankarabakkal@gmail.com

3 Prof. Dr., Marmara Üniversitesi, İşletme Fakültesi, Örgütsel Davranış Bölümü
} 


\title{
The Opinions of Public R \& D Employees on Causes of Conflict and Functional Conflict Management Skills
}

\begin{abstract}
This research is an explorative study that aims to contribute to the understanding of the causes of conflicts and the functional conflict management skills in public research and development centers. At the beginning of the study, interviews were conducted with 14 employees, 4 project executives, 3 professional trainers, and 2 academicians from the research population through semi-structured interview forms. The qualitative data were analyzed with MAXQDA 2018. 02 program and a quantitative data collection tool was developed in light of the qualitative analysis findings. Then, by using a convenient sampling method, quantitative data were collected from $133 \mathrm{R} \& \mathrm{D}$ employees (46 females and 87 males) regarding their perceptions of the factors that cause conflicts in organizations and their perceived effective conflict management skills. The quantitative data were analyzed with SPSS 22 program by using the descriptive analysis method and the findings were discussed in terms of the learning and development needs of employees.
\end{abstract}

Keywords: Causes of Conflict, Functional Conflict Management Skills, R \& D Institutions, Learning and Development Needs.

\section{GİRiş}

Çatışmalar, iş hayatının ayrılmaz bir parçasıdır. Araştırmalar; çatışmayla ilgili farkındalığın arttıılmasının ve beceri geliştirme konusunda çalışanların ihtiyaçlarına uygun eğitim bileşenlerinin tespit edilmesinin, çatışmaların üstesinden gelme üzerindeki etkisine işaret etmektedir (Aydın, 2015; Sucuoğlu, 2015). Ancak, çalışanların mevcut farkındalıkları ve becerileri çatışma durumlarıyla başa çıkmaları için uygun ve yeterli olmayabilir. Böyle bir durum, özellikle yoğun zihinsel iş yüküne sahip Ar-Ge organizasyonlarındaki çalışanları daha çok etkilemektedir. Ancak, işlevsel çatışma yönetimi beceri geliştirme programları ile istenmeyen bu sonuçları azaltmak mümkündür. Geliştirilecek eğitim ve gelişim programları açısından, kurumların iş yapma kültürleri ile amaçları doğrultusundaki ihtiyaçlarının merkeze alınması kritik bir öneme sahiptir. Bu nedenle söz konusu çalışma, kamuya bağlı Ar-Ge merkezlerindeki çalışanların işlevsel çatışma yönetimi becerilerini geliştirmeyle ilgili öğrenme ve gelişim ihtiyaçlarına 1şık tutmak amacıyla yürütülmüştür. Ar-Ge çalışanları, Ar-Ge proje 
yürütücüleri, profesyonel eğiticiler ve konu üzerine araştırmaları bulunan akademisyenlerden toplanan nitel veriler ile yine Ar-Ge çalışanlarından toplanan nicel verilerin analizlerini bütünleşik olarak ele alan sonuçlar ortaya koyulmuştur.

\section{KAVRAMSAL ÇERÇEVE}

Çatışma bireyler arasındaki düşünce, değer ve duygu farklılıklarından kaynaklanan, özel ve örgütsel yaşantımızda karşılaştığımız, strese neden olan, kaçınılmaz ve karmaşık bir olgudur (Marquis ve Huston, 2000). Kavramsal olarak algılardaki farklılıklar, anlaşmazlık, fikir uyuşmazlığı ve gerçeklerin yorumlanmasındaki değişiklikler ile ilişkilendirilen çatışmaların (Ayoko vd., 2002; Rahim, 2001); nedenleri, türleri ve sonuçları bakımından doğru anlaşılmasının etkin çatışma yönetimi adına önemli olduğu düşünülmektedir.

\section{1. Çatışmanın Nedenleri}

Çatışmanın nedenleri örgütsel ve bireysel nedenler olarak iki ana grupta incelenebilir (Opatha, 2015). Çatışmanın örgütsel açıdan nedenlerine bakıldığında araştırmalar; zamanın ve finansal imkânların kısıtlı olması, hedeflerin uyumsuz oluşu, rol ve sorumluluklarda belirsizlik, takım canlılığının eksik oluşu gibi birçok farklı etmene işaret etmektedir (Aswathappa ve Ready, 2009; Balkundi ve Harrison, 2006; Cheong ve Kim, 2017; De Dreu ve Gelfand, 2008). Ayrıca görev ile hedeflerde karşılıklı bağımlılığın (Schaeffner vd., 2015) ve örgütsel yaşamdaki karmaşıklığın (Jehn, 1995) da çatışmaları beraberinde getirdiğine dair çalışmalar bulunmaktadır.

Çatışmanın bireysel nedenlerine bakıldığında ise araştırmalar; algısal ön yargıları (Baron, 1991), kişiler arasındaki güvene dayalı ilişkilerin sınırlı oluşunu (Curseu, 2006), çalışanlar arasındaki artan etkileşimi (Gladstein, 1984), çalışanlar arasındaki farklı yetkinlik düzeylerini, iletişim becerilerinin yetersiz oluşunu veya çalışanların iletişim kurmakta isteksiz oluşlarını, kişilik ve değer yargıları açısından farklılıklar ile çalışanların algıladıkları eşitsizlik ve adaletsizlik duygusunu ortaya koymaktadır (Opatha, 2015). Bunun dışında çatışmanın ortaya çıkmasında duygusal uyarılmanın ve duygusal açıdan aşırı yüklenmenin rolünü araştıran bazı çalışmalar (Bodtker ve Katz Jameson, 2001; Gayle ve Preiss, 1998; Jehn, 1997; Jehn ve Bendersky, 2003; Nair, 2008) da bulunmaktadır. Ayrıca belirsizlik durumlarında insanların kendi istek ve düşüncelerini merkeze alarak yaptıkları öznel yorumların ve atıfların da çatışmaları beraberinde getirdiği görülmektedir (Bodtker ve Katz Jameson, 2001; Heider, 1958). 


\section{2. Çatışmanın Türleri}

Çatışmanın türleri konusunda Rahim (2001) bireysel düzeyde bir değerlendirmede bulunmuş ve çatışmaları bireyin kendi içinde yaşadığı çatışmalar ve bireyler arasında yaşanan çatışmalar olarak ele almıştır. Öte yandan, Jehn (1995), çatışmaları grup içinde yaşanan çatışmalar bakış açısından ele alarak çatışmanın yararları ve zararları konusunda öncü bir çalışma yapmış ve çatışmaları ilişki çatışması ve görev çatışması olmak üzere iki ana kategoride sınıflandırmıştır. Devamında ise Jehn ve Mannix (2001) yaptıkları çalışmalarda süreç çatışmasından da bahsetmişlerdir.

İlişki çatışmaları; kişilik farklılıkları, farklı değerler ve duygusal konular gibi kişilerarası meseleler hakkında grup üyeleri arasındaki anlaşmazlıklarla ilişkilidir (Jehn ve Bendersky, 2003). Bunun yanında, kişilerarası uyumsuzlukların, grup üyeleri içindeki gerginlikler ile sıkıntıların ve kişisel kimliğe yönelik algılanan tehdit gibi unsurların da ilişki çatışmalarıyla ilişkilendirildiği görülmüştür (Jehn, 1995; Pelled, 1996). Yapılan araştırmalar ilişki çatışmasının kurumlardaki en önemli zaman çalıcılardan olduğunu göstermiştir, çünkü çalışanlar haklı olduklarını muhataplarına kabul ettirme amacıyla tartışmaları sürdürme eğiliminde olmaktadırlar (Jehn, 1995). Bunun dışında ilişki çatışmaları, çalışanların iş doyumlarını ve duygusal durumlarını da olumsuz yönde etkilemektedir (Guerra vd., 2005).

Diğer bir çatışma türü görev çatışmasıdır ve gerçekleştirilecek görevin içeriğine ilişkin uyuşmazlıklar (Jehn, 1995) ile kaynakların dağılımı ve karar verme usullerinin belirlenmesi konusundaki algısal farklılıklar olarak tanımlanmaktadır (De Dreu ve Weingart, 2003). Ekip üyeleri alışılmış bir usule meydan okuduklarında ya da yaygın olarak kabul edilen yöntemleri sorguladıklarında, bu durum bazı üyelerce saygısızlık olarak değerlendirilebilmektedir (Fiske ve Taylor, 1991). Öte yandan, farklı görüşlerin teşvik edilmesinden ve şeytanın avukatlığı rolünün yanılgıları ortaya koymasından dolayı görev çatışmasının karar alma kalitesini ve yaratıcı fikirleri geliştirebileceği de araştırmalarda belirtilmiştir (Amason, 1996; Simons ve Peterson, 2000).

Son olarak, süreç çatışması, Jehn'in (1997) kapsamlı araştırması sonucunda, ekip yapısının nasıl oluşturulacağı ve iş yüklerinin verimli bir şekilde nasıl dağıtılacağı gibi görevlerin yerine getirilmesi konusundaki anlaşmazlıklar olarak tanımlanmıştır. Bu noktada süreç çatışmasının; çalışanların moralini bozması, kuruma olan bağlılıklarını ve performanslarını azaltması ve ekibin hedeflerine ulaşma coşkusunu tahrip etmesi açılarından 


\section{MAKÜ-BIFD 3(1), 7-27, 2020}

diğer çatışma türleriyle karşılaştırıldığında daha zararlı ve daha karmaşık olduğu ortaya koyulmuştur (Jehn ve Bendersky, 2003).

\section{3. Çatışmanın Sonuçları}

Çatışmalar nasıl ele alınıp yönetildiklerine bağlı olarak işlevsiz ya da işlevsel sonuçlara neden olabilmektedir. Çatışmalar doğru ele alındıklarında işbirliğine ve yapıcı değişimlere yol açabildikleri gibi, doğru ele alınmadıklarında kaygı durumunu tetiklemekte ve kişileri savunmacı bir tutuma sevk edebilmektedir (Coleman ve Deutsch, 2000).

Örneğin, doğru ele alınmayan çatışmaların, çalışanların hedef odaklı davranışlarını engelleyebildiği ve kaygı, korku ve suçluluk gibi olumsuz duyguları üretebildiği ifade edilmektedir (Bruk-Lee ve Spector, 2012). Böyle durumlarda çalışanların ilişkilerinde suçlayıcı söylemler yaygın bir biçimde görülebilmektedir (Hocker ve Wilmot, 1998). Buna ek olarak, etkin yönetilmeyen çatışmaların yapıcı iletişime engel olduğu, grup üyeleri arasındaki işbirliğini zayıflattığı ve kurumdaki rekabet duygusunu azalttığı görülmüştür (Baron, 1991). Zira çalışanların grup aidiyetlerine zarar vermesi açısından işlevsiz çatışmalar, kişiler arasındaki güven duygusunun ve saygının azalmasına ve yine buna bağlı olarak çalışanların ekibin diğer üyeleriyle uyumlu çalışmalarının engellenmesine yol açabilmektedir (Jehn vd., 2008). Tüm bunlar ise çalışanlar arasındaki olumsuz duyguların artmasına, çatışmaların daha da tırmanmasına (Dijkstra vd., 2009) ve kurumlardaki üretkenliğin ve iş performansının düşmesine neden olabilmektedir (Meyer, 2004).

Öte yandan, çatışmalar etkin bir şekilde ele alındıklarında etkili problem çözme stratejilerinin geliştirilmesinde önemli bir rol oynayabilirler. Örneğin, çatışmalar; birden çok bakış açısının ele alınmasına fırsat vererek eleştirel düşünceyi teşvik ederse, etkili karar verme sürecine destek olup işlevsel bir rol icra edebilirler (Jehn ve Bendersky, 2003). Yine araştırmalar göstermektedir ki çatışmalar doğru anlaşılıp doğru yönetildiklerinde işlevsel bir hal almakta ve esnek düşünce ile yaratıcı problem çözme stratejilerinin uygulanma olasılıklarını arttırmaktadırlar (Carnevale ve Probst, 1998). Ayrıca; etkin yönetilen çatışmalar kurumlarda ekip üyeleri arasındaki uyum ve ahengin de güçlenmesine destek olmakta (Schermerhorn vd., 2000), çalışanların psikolojik sermayelerinin güçlenmesine (Oore, Leiter ve LeBlanc, 2015) imkan sağlamakta ve çalışanlar arasındaki zorbalık davranışlarının azalmasına katkı sunmaktadır (Baillien vd., 2009).

$\mathrm{Bu}$ noktada literatürde olumlu iş sonuçlarıyla anılan işlevsel çatışma yönetimi becerilerinin geliştirilmesinde, çatışmanın nedenleriyle ilgili öne çıkan etmenlerin ve etkin 
yönetilmesinde en çok ihtiyaç duyulan becerilerin doğru tespit edilmesinin kritik bir önem taşıdığı görüşü araştırmacılarca paylaşılmaktadır.

\section{ARAŞTIRMANIN YÖNTEMI}

\subsection{Araştırma Modeli ve Örneklem}

$\mathrm{Bu}$ araştırma temelde keşifsel ve tanımlayıcı nitelikte bir çalışmadır. Çalışmanın katılımcı grubu kolaylıkla erişilebilen örnekleme (convenience sampling) yolu ile kamuya bağglı araştırma enstitülerinde görev yapan 133 (46 kadın - \%34,59 ve 87 erkek - \%65,41) Ar-Ge personelinden oluşturulmuştur. Veri toplama araçlarının geliştirilmesi öncesinde, çatışma nedenleri ve başarılı çatışma yönetimi gibi konularda yüz yüze mülakat yoluyla 14 çalışan (5 kadın ve 9 erkek), 4 proje yöneticisi (4 erkek), 3 profesyonel eğitici (2 kadın ve 1 erkek) ve 2 akademisyene (1 kadın Prof. ve 1 erkek Prof. ) görüşleri sorulmuştur. Örneklemde yer alan 133 katılımcının yaş, kıdem ve eğitim durumlarına ilişkin dağılımlar Tablo 1'de verilmiştir.

Tablo 1. Katılımcıların yaş, kıdem ve eğitim dağılımları

\begin{tabular}{lcccccccccccc}
\hline & & \multicolumn{4}{c}{ YAS } & \multicolumn{4}{c}{ KIDEM } & \multicolumn{3}{c}{ EĞiTiM (\%) } \\
\hline CINSIYYET & $\mathrm{N}$ & Min & Max & $\mathrm{X}$ & $\mathrm{N}$ & Min & Max & $\mathrm{X}$ & $\begin{array}{c}\text { Lisans } \\
\text { Yüksek }\end{array}$ & $\begin{array}{c}\text { Doktora } \\
\text { Lisans } \\
\text { ve Sonras1 } \\
(\%)\end{array}$ \\
\hline Kadın & 46 & 21 & 55 & 32,8 & 46 & 1 & 26 & 6 & $50 \%$ & $41,30 \%$ & $8,70 \%$ \\
Erkek & 87 & 24 & 63 & 34,3 & 87 & 1 & 35 & 6,28 & $37,93 \%$ & $44,83 \%$ & $17,24 \%$ \\
TOPLAM & 133 & 21 & 63 & 33,8 & 133 & 1 & 35 & 6,18 & $42,11 \%$ & $43,61 \%$ & $14,28 \%$ \\
\hline
\end{tabular}

Not: Yaş ve kıdem süreleri yıl üzerinden hesaplanmıştır. Min = asgari, Max = azami.

\section{2. Ölçüm Araçları}

Çalışmada; Yarı Yapılandırılmış Mülakat Formu (Çalışan, Proje Yöneticisi, Profesyonel Eğitici ve Akademisyen) ile Çatışmayı Tetikleyen Nedenler ve Başarılı Çatışma Yönetim Becerileri Formunu kapsayan iki adet ölçüm aracı kullanılmıştır.

\subsubsection{Yarı Yapılandırılmış Mülakat Formu}

Yarı yapılandırılmış mülakat formu soruları çalışanların, proje yürütücülerinin, profesyonel eğiticilerin ve akademisyenlerin çatışmayı tetikleyen nedenler ve başarılı çatışma yönetim becerileri konusundaki görüşlerini almak için araştırmacı tarafından geliştirilmiştir. Tüm formlarda çatışmanın nedenleri ve başarılı çatışma yönetimiyle ilgili 2 adet açık uçlu soru ortak olarak yer almıştır. Çalışma öncesinde mülakat soruları dil ve anlatım açısından pilot 
uygulama ile sınanmış ve geri bildirimlere dayalı olarak son haline getirilmiştir. Aşağıda, nicel veri formunun geliştirilmesinde kullanılan içerik analizi sonuçlarının MAXQDA programında oluşturulan sıklık dağılımları tablolar halinde sunulmuştur.

Tablo 2. Çatışmayı tetikleyen nedenler - çalışan görüş analizleri

\begin{tabular}{|c|c|c|}
\hline Kod Sistemi & Çalışan & TOPLAM \\
\hline (.) Başkalarını Memnun Etme Çabası & & 2 \\
\hline B. Birbirine Bağımlı İşler (task-interdependency) & & 2 \\
\hline (e) Çalışanlarda Sorumluluk Duygusunun Azlığı & & 6 \\
\hline ๑.) Çalışanların İşlerini Tutkuyla Yapmayışları & & 1 \\
\hline @. Çatışma Yönetimiyle ilgili Bilgi/Deneyim Eksikliği & & 7 \\
\hline (-) Çatışmaya Yüklenen Farklı Anlamlar & $\bullet$ & 4 \\
\hline$@$ Dedikodu & & 3 \\
\hline (-) Duygu Kontrolü/Yönetiminde Sorunlar & & 7 \\
\hline$\sigma_{\odot}$ Ekip Ruhu Eksikliği & $\bullet$ & 5 \\
\hline Etik Dışı Davranışlar & $\bullet$ & 3 \\
\hline @.) Farklı İş Yapma Biçimi & 0 & 5 \\
\hline$\varrho_{\ominus}$ İlişki Yönetiminde Sorunlar & • & 4 \\
\hline (-) İş Dağılımnnda/Bölümünde Adaletsizlik & & 6 \\
\hline (e) İş Süreçlerine Hakim Olmayış & $\bullet$ & 2 \\
\hline (.) Işi Kısa Sürede Bitirme Baskısı & • & 4 \\
\hline @. Kıskançlık ve Öne Çıkma İsteği & & 8 \\
\hline (.) Suçlayııı Dil ve İletişim & & 7 \\
\hline G. Tarafların Yanlış Kaynaktan Bilgi Edinmeleri & - & 1 \\
\hline ๑. Yöneticinin İşle İlgili Aşırı Beklentisi & - & 2 \\
\hline$\Sigma$ TOPLAM & 79 & 79 \\
\hline
\end{tabular}

Çalışanların çatışmayı tetikleyen nedenler konusunda sıklıkla; kıskançlık ve öne çıkma isteği, iletişimde suçlayıcı bir dil kullanma, duyguları kontrol etme ve yönetmede sorunlar yaşama ve çatışma yönetimi konusunda yeterince bilgi ve tecrübe sahibi olmama gibi görüşler belirttikleri görülmüştür. 
Karabakkal H, Torun A.

Tablo 3. Çatışmayı tetikleyen nedenler - proje yöneticisi görüş analizleri

\begin{tabular}{|c|c|c|}
\hline Kod Sistemi & Yönetici & TOPLAM \\
\hline @- Çalışanlarda Sorumluluk Duygusunun Azlığı & - & 1 \\
\hline C.e Çalışanlann İşlerini Tutkuyla Yapmayışlanı & & 3 \\
\hline Duygu Kontrolü/Yönetiminde Sorunlar & & 4 \\
\hline Ekip Ruhu Eksikliği & & 3 \\
\hline ๑.] Etik Dışı Davranışlar & - & 1 \\
\hline •. Farklı İ̧̧ Yapma Biçimi & - & 2 \\
\hline${ }_{\oplus}$ İs Süreçlerine Hakim Olmayış & ? & 2 \\
\hline ๑.] Kıskançllk ve Öne Çıkma İsteği & O & 3 \\
\hline Kişilerarası Güven Eksikliği & O & 3 \\
\hline @- Suçlayıcı Dil - İletişim Problemleri & ○ & 3 \\
\hline$\Sigma$ TOPLAM & 25 & 25 \\
\hline
\end{tabular}

Not: 4 proje yöneticisinin görüşleri analiz edilmiştir.

Proje yürütücülerinin çatışmayı tetikleyen nedenler konusunda sıklıkla; çalışanların duygularını kontrol etme ve yönetmede sorunlar yaşamaları, işlerini tutkuyla yapmamaları, ekip ruhu duygularının gelişmemiş olmaması, kıskançlık ve öne çıkma isteklerinin baskın olması, kişiler arası ilişkilerinde güven duygularının eksik oluşu ve iletişimleri esnasında suçlayıcı bir dil kullanmaları gibi görüşler belirttikleri görülmüştür.

Tablo 4. Çatışmayı tetikleyen nedenler - profesyonel eğitimci görüş analizleri

\begin{tabular}{|c|c|c|}
\hline Kod Sistemi & Profesyonel Ëgitici & TOPLAM \\
\hline$\odot_{\bullet}$ Çatıs̆ma Yönetimi Hakkında Bïgi/Deneyim Eksikliği & - & 2 \\
\hline$\bigodot_{-}$Çatışmanın Nedenlerini Doğru Analiz Edememe & $\bullet$ & 1 \\
\hline C. Çatışmaya Yüldenen Farkı Anlamlar & - & 2 \\
\hline e. Dinleme Hatalan & $\bullet$ & 1 \\
\hline$e_{\bullet}$ Duygu Kontrolü/Yönetiminde Sorunlar & - & 2 \\
\hline$\bigodot_{\bullet}$ Ekip Ruhu Eksildig̈i & $\bullet$ & 1 \\
\hline Empati Eksikliği & $\bullet$ & 1 \\
\hline @ İnsana Verilen Değerin Unvan ve Statü ile İlişkilendirilmesi & 루 & 3 \\
\hline$e_{\bullet}$ Iș Yerinde Güven Eksikliği & - & 1 \\
\hline ๑. Kuskançlik ve Öne Çıkma İsteği & - & 3 \\
\hline @ Suçlayic Dil - Iletişim Problemieri & $\bullet$ & 1 \\
\hline$e_{-}$Varsaymlann Karar Verme Uzerindeki Etkileri & - & 2 \\
\hline$\Sigma$ TOPLAM & 20 & 20 \\
\hline
\end{tabular}

Not: 3 profesyonel eğitimcinin görüşleri analiz edilmiştir.

Profesyonel eğitimcilerin çatışmayı tetikleyen nedenler konusunda sıklıkla; insana verilen değerin unvan ve statü ile ilişkilendirilmesi, iş yerinde kıskançlık ve öne çıkma isteğinin yaygın olması gibi görüşler belirttikleri görülmüştür. 
Tablo 5. Çatışmayı tetikleyen nedenler - akademisyen görüş analizleri

\begin{tabular}{|c|c|c|}
\hline Kod Sistemi & Akademisyen & TOPLAM \\
\hline$\bigodot_{e}$ Birbirine Bağınl İșler (task-interdependency) & - & 1 \\
\hline e. Çalışanların İşlerini Tutkuyla Yapmayıșlan & - & 1 \\
\hline C Çatışma Yönetimi Hakkında Bilgi/Deneyim Eksikliği & - & 2 \\
\hline ๑. Çatışmada Arkadaşların Taraf Olmalannı Bekleme & $\bullet$ & 1 \\
\hline CDuygu Kontrolü/Yönetiminde Sorunlar & (-) & 2 \\
\hline$\bigodot_{\bullet}$ Farki Iş Yapma Biçimi & (e) & 2 \\
\hline$\bigodot_{\oplus}$ Görev Tanımiannın Net Olmayışı & - & 1 \\
\hline$\odot_{-}$İlişkj Yönetiminde Sorunlar & - & 1 \\
\hline$\ominus_{e}$ İs Bölümù Adaletsizliği & (2) & 2 \\
\hline$e_{\bullet}$ İş Süreçlerinin Net Olmayışı & - & 1 \\
\hline @e Iş Yerinde Güven Eksikliği & (1) & 2 \\
\hline @Önemli Bilgileri Saklama/Paylaşmama & $\bullet$ & 1 \\
\hline •.) Suçlayıcı Dil - Iletişim Problenteri & D & 2 \\
\hline$\Sigma$ TOPLAM & 19 & 19 \\
\hline
\end{tabular}

Not: 2 akademisyenin görüşleri analiz edilmiştir.

Akademisyenlerin çatışmayı tetikleyen nedenlerle ilgili sıklıkla; çatışma yönetimi hakkında bilgi ve tecrübe eksikliği, duyguların kontrolü ve yönetiminde sorunlar yaşanması, çalışanların iş yapma biçimlerinin farklı oluşu, iş bölümünde adaletsiz uygulamalar, iş yerinde güven duygusunun çok az olduğunun düşünülmesi ve iletişim esnasında suçlayıcı bir dil kullanma gibi görüşler belirttikleri görülmüştür.

Tablo 6. Başarılı çatışma yönetim becerileri - çalışan görüş analizleri

\begin{tabular}{|c|c|c|}
\hline Kod Sistemi & Çalışan & TOPLAM \\
\hline Anlașimayı Beklememe, Kendini Anlatma & •. & 1 \\
\hline @ Çatışma Yönetimine Kazan-Kazan Olarak Bakma & $\bullet$ & 3 \\
\hline$\odot_{\bullet}$ Çatışmanın Nedenlerini Doğru Anlama & & 10 \\
\hline @ Çatışmaya Konu Sorun Alanı Dışına Çıkmama & $\cdot$ & 2 \\
\hline @ Duygulann Etkin Kontrol ve Yönetimi & $\bullet$ & 5 \\
\hline C. Etkin Dinleme (Taraflarin İhtiyaçlarını Anlama Amaçh) & ? & 8 \\
\hline C. Farkdilklara Açık Olma & - & 2 \\
\hline Kendini Doğru İfade Edebilme & - & 6 \\
\hline @Ortak Çözüm Yolları için Birlikte Çalışma & $\bullet$ & 4 \\
\hline$\odot$ Özeleştiri Yapma & $\bullet$ & 3 \\
\hline$\odot_{-}$Profesyonelliğin Temel Odakta Kalması & $\bullet$ & 3 \\
\hline$\sum$ TOPLAM & 47 & 47 \\
\hline
\end{tabular}

Not: 14 çalışanın görüşleri analiz edilmiştir. 


\section{Karabakkal H, Torun A.}

Çalışanların başarılı çatışma yönetimi becerileriyle ilgili sıklıkla; çatışmanın nedenlerini doğru anlama, çatışmaya taraf olanların ihtiyaçlarını anlama amaçlı etkin dinleme ve kendini doğru ifade edebilme gibi görüşler belirttikleri görülmüştür.

Tablo 7. Başarılı çatışma yönetim becerileri - proje yöneticisi görüş analizleri

\begin{tabular}{|c|c|c|}
\hline Kod Sistemi & Yönetici & TOPLAM \\
\hline Çatışma Yönetimine Kazan-Kazan Olarak Bakma & - & 2 \\
\hline Çatışmanin Nedenlerini Doğru Anlama & ? & 3 \\
\hline C. Duyguların Etkin Kontrolü ve Yönetimi & - & 2 \\
\hline Etkin Dinleme (Tarafların İhtiyaçlarını Anlama Amaçı) & - & 4 \\
\hline$G$ Iş Tanımarının Net Olması & $\bullet$ & 1 \\
\hline Kendini Doğru İfade Edebilme & - & 2 \\
\hline Ortak Çözüm Yolları için Birlikte Çalışma & $\bullet$ & 1 \\
\hline @Özeleștiri Yapma & ? & 4 \\
\hline S Sabirlı Olma & $\bullet$ & 1 \\
\hline$\sum$ TOPLAM & 20 & 20 \\
\hline
\end{tabular}

Not: 4 proje yürütücüsünün görüşleri analiz edilmiştir.

Proje yürütücülerinin başarılı çatışma yönetimi becerileriyle ilgili sıklıkla; çatışmaya taraf olanların ihtiyaçlarını anlama amaçlı etkin dinleme, öz eleştiri yapabilme ve çatışmanın nedenlerini doğru anlama gibi görüşler belirttikleri görülmüştür.

Tablo 8. Başarılı çatışma yönetim becerileri - profesyonel eğitimci görüş analizleri

Kod Sistemi

๑Özeleștiri Yapma

๑ Ortak Çözüm Yollan Olduğuna İnanma

‥ Muhatabi Tanma ve İtiyaçlann Anlama

C. Kendini Tanma ve Blime

Etkin Dínleme (Taraflann İhtiyaçlannı Anlama Amaçh)

C. Etkin Çözüm İ̧in Gayret Etme ve Gönüitui Olma

Düşünce Kalplann ve Varsaymian Kirma

CDuygularn Etkin Kontrolü ve Yönetimi

(C) Çatıs̆mannn Nedenlerini Doğru Anlama

Anlaştmayı Beklememe, Kendini Anlatma

- Anda Kalma ve An Yönetme

$\sum$ TOPLAM

Not: 3 profesyonel eğitimcinin görüşleri analiz edilmiştir.
Profesyonel Eğgitici TOPLAM

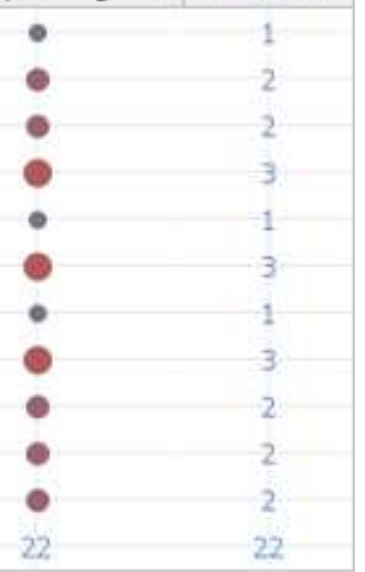

22
27

Profesyonel eğitimcilerin başarılı çatışma yönetimi becerileriyle ilgili sıklıkla; kendini tanıma ve bilme, çatışmanın etkin çözümü için gayret etme ve bu konuda gönüllü olma ile duyguları etkin biçimde kontrol etme ve yönetme gibi görüşler belirttikleri görülmüştür. 
Tablo 9. Başarılı çatışma yönetim becerileri - akademisyen görüş analizleri

\begin{tabular}{|c|c|c|}
\hline Kod Sistemi & Akaderrisyen & TOPLAM \\
\hline ๑e Çatışma Yönetimini Kişisel Bir Zafer Kazanma Olarak Görmeme & ? & 2 \\
\hline${ }_{8}$ Çatıs̆manin Nedenlerini Doğru Anlama & (2) & 2 \\
\hline ๑. Etkin Çözüm İ̧̧in Gayret Etme ve Gönüllü Olma & $\bullet$ & 1 \\
\hline @Etkin Dinleme (Taraflann Ihtiyaçlarını Anlama Amaçli) & - & 2 \\
\hline$\odot_{-}$Farklikdara Saygı Duyma/Kabul Etme & - & 2 \\
\hline${ }_{-}$Is Yerinde Iliski Yönetimi & - & 1 \\
\hline @ Kendini Doğru Ifade Edebilme & (2) & 2 \\
\hline$e_{0}$ Odağin Ortak thtiyas, Amas ve Menfaatlerde Olması & (1) & 2 \\
\hline${ }_{\theta}$ Profesyonelliğin Temel Odakta Kalması & - & 2 \\
\hline CZamani Etkin Kullanma & $\bullet$ & 1 \\
\hline$\Sigma$ TOPLAM & 17 & 17 \\
\hline
\end{tabular}

Not: 2 akademisyenin görüşleri analiz edilmiştir.

Akademisyenlerin başarılı çatışma yönetimi becerileriyle ilgili sıklıkla; çatışma yönetimini kişisel bir zafer kazanma olarak görmeme, çatışmanın nedenlerini doğru anlama, tarafların ihtiyaçlarını doğru anlamak için etkin dinleme, farklılıklara saygı duyma ve onları kabul etme, kendini doğru ifade etme, odağı ortak ihtiyaç, amaç ve menfaatlerde tutabilme ve iş yerinde profesyonelliği temel odakta tutma gibi görüşler belirttikleri görülmüştür.

Sonuç olarak, nitel verilere göre, çatışmaya yol açan nedenler arasında, "iş bölümünde adaletsizlik" gibi ortamsal özelliklerden çok "kıskançlık ve suçlayıcı dil kullanımı” gibi bireysel özelliklere ağırlık verilmiştir. Çatışma yönetimi becerilerinin başarısı açısından ise "çatışan tarafların ihtiyaçlarını anlama" gibi bilişsel ve "duyguların etkin bir biçimde denetimi" gibi duygusal yöntemler üzerinde durulmuştur.

\subsection{2. Çatışmayı Tetikleyen Nedenler ve Başarılı Çatışma Yönetim Becerileri Formu}

$\mathrm{Bu}$ form, mülakatlarla toplanan nitel verilerin içerik ve sıklık analizi sonuçları dikkate alınarak, Ar-Ge kurumlarında karşılaşılan çatışmaların nedenlerinin ve kullanılabilecek işlevsel çatışma yönetim becerilerinin ortaya koyulmasıyla ilgili nicel veri toplamak üzere araştırmacı tarafından geliştirilmiştir.

Formun çatışmanın nedenleriyle ilgili kısmında 25 soru; etkili çatışma yönetim becerileriyle ilgili kısmında ise 20 soru yer almıştır. Katılımcılar formda yer alan sorulara cevaplarını 4'lü bir derecelendirme ölçeği üzerinde işaretlemişlerdir (1: kesinlikle katılmıyorum - 4: kesinlikle katılıyorum). 


\subsection{Uygulama}

Çalışmanın başında, araştırma evrenine mensup 14 çalışan ve 4 proje yürütücüsü ile yüz yüze görüşmeler gönüllülük ilkesine göre yapılmıştır. Deneyimlerine istinaden 3 profesyonel eğitimci ve 2 akademisyen ile de yüz yüze görüşülmüştür. Görüşmeler katılımcıların sorulara cevap vermesine uygun bir ortamda yapılmış, çözümlenmiş ve sahiplerine teyit ettirilmiştir. Görüşme yapılan kişiler, örnekleme dâhil edilmemiştir.

Nitel veri analizleri akabinde, nicel veri toplamak için geliştirilen formun araştırma evrenine duyurulması için kurum yönetiminden izin alınmıştır. Form, çevrimiçi anket sistemi aracılığıyla 133 katılımcı tarafından doldurulmuştur.

\subsection{Analiz}

Mülakat çözümleri MAXQDA 2018.02 (VERBI Software, 2018) programına yüklenmiş, satır-satır analiz (line by line analysis) yaklaşımı ile veriler kodlanmış; her kelime, kelime grupları ve cümleler analiz için dikkate alınmıştır (Patton, 2014). Kodlama sürecinde açık, eksensel ve seçici kodlama tekniklerinden; verileri yorumlama sürecinde ise araştırmanın amacı doğrultusunda tümevarıma dayalı (inductive) betimsel analizden ve içerik analizinden yararlanılmıştır (Demir ve Bütüner, 2014; Marshall ve Rossman, 2011; Miles ve Huberman, 1994). Son aşamada, temalara ayrılmış veriler üzerinde sistematik anlam bütünlüğü sağlanmış ve süreç tamamlanmıştır. Nicel verilerin analizi ise SSPS Statistics 22 programı ile tanımlayıcı analiz yöntemi kullanılarak (ortalamaların ve standart sapmaların hesaplanmasi) gerçekleştirilmiştir. Tablolarda, en yüksek ortalamaya sahip 5 madde ile ilgili sonuçlara yer verilmiştir.

\section{BULGULAR}

\subsection{Nicel Bulgular}

Katılımcıların çatışmayı tetikleyen nedenler hakkındaki düşünceleriyle ilgili tanımlayıcı analizler yapılmıştır. Asgari puanın 1, azami puanın 4 olduğu puanlama sistemindeki analiz sonuçlarına göre, "Illetişim sırasında suçlayıcı bir dil kullanma”" maddesi (X=3,50 ve $\mathrm{S}=0,64)$ en yüksek puan ortalamasına sahip olmuştur. Bu maddeyi, "Dinleme hataları, muhatabı anlama gayesiyle dinlememe" ( $\mathrm{X}=3,41$ ve $\mathrm{S}=0,69)$ ve "Klskançlık ve öne çıkma isteği”" (X $=3,41$ ve $S=0,69$ ) maddeleri takip etmiştir. Bu maddelerin ardından, sırasıyla "Çalışanların görev tanımlarının yeterince net olmayışı” $(\mathrm{X}=3,38$ ve $\mathrm{S}=0,73)$ ve "Kişiler arasındaki güven eksikliğì" ( $\mathrm{X}=3,38$ ve $\mathrm{S}=0,69)$ maddeleri ortaya çıkmıştır. Son olarak, "Kişilerin empati gösterme konusundaki eksiklikleri" $(\mathrm{X}=3,36$ ve $\mathrm{S}=0,67)$ ve "Duyguların kontrolü ve etkin 
aktarımında karşılaşılan güçlükler” $\mathrm{X}=3,32$ ve $\mathrm{S}=0,67$ ) maddeleri de yüksek değer alan maddeler arasında yer almıştır. Çatışmayı tetikleyen nedenlerden öne çıkan 7 maddenin tanımlayıcı istatistiklerine Tablo 10 'da yer verilmiştir.

Tablo 10. Çatışmayı tetikleyen nedenlerin tanımlayıcı istatistikleri

\begin{tabular}{clcc}
\hline \multirow{2}{*}{ MADDE } & \multicolumn{1}{c}{$\begin{array}{c}\text { ÇATIŞMAYI TETIKLEYEN NEDENLERİN } \\
\text { TANIMLAYICI İSTATISTIKLERİ }\end{array}$} & X & $\mathrm{S}$ \\
\cline { 2 - 4 } & \multicolumn{1}{c}{ İletişim sırasında suçlayıcı bir dil kullanma } & 3,50 & 0,64 \\
2 & Dinleme hataları, muhatabı anlama gayesiyle dinlememe & 3,41 & 0,69 \\
3 & Kıskançlık ve öne çıkma isteği & 3,41 & 0,69 \\
4 & Çalışanların görev tanımlarının yeterince net olmayışı & 3,38 & 0,73 \\
5 & Kişiler arasındaki güven eksikliği & 3,38 & 0,69 \\
6 & Kişilerin empati gösterme konusundaki eksiklikleri & 3,36 & 0,67 \\
7 & $\begin{array}{l}\text { Duyguların kontrolü ve etkin aktarımında karşılaşılan } \\
\text { güçlükler }\end{array}$ & 3,32 & 0,67 \\
\hline
\end{tabular}

$\mathrm{N}=133, \mathrm{X}$ : ortalama değer; en az 1 , en çok 4 puan, $\mathrm{S}$ : standart sapma

Tanımlayıcı analizler, katılımcıların başarılı çatışma yönetimi becerileri hakkındaki düşünceleriyle ilgili de gerçekleştirilmiştir. Asgari puanın 1, azami puanın ise 4 olduğu puanlama sistemindeki analiz sonuçlarına göre "İletişime açık olma" maddesi $(\mathrm{X}=3,57$ ve $\mathrm{S}$ $=0,53$ ) en yüksek puan ortalamasına sahip olmuştur. Bu maddeyi “Empati gösterme (önce anlamaya çalışmak, sonra anlaşılmayı beklemek) $(\mathrm{X}=3,54$ ve $\mathrm{S}=0,58)$ ve "Muhatabın ihtiyaçlarını ve kaygılarını anlamak için dinleme" (X $=3,50$ ve $\mathrm{S}=0,57)$ maddeleri takip etmiştir. Bu maddelerin ardından, sırasıyla "Çatışmayı tırmandıracak söz ve eylemlerden kaçınma" ( $\mathrm{X}=3,48$ ve $\mathrm{S}=0,68)$ ve "Çatışmayı kişisel bir zafer kazanma gayesine taşımama" $(\mathrm{X}=3,46$ ve $\mathrm{S}=0,71)$ maddeleri ortaya çıkmıştır. Son olarak, "Arkadan konuşmama, dedikoduya yer vermeme" ( $\mathrm{X}=3,46$ ve $\mathrm{S}=0,70$ ) ve "Çatışmayı çözme konusunda çaba sarf etmeye gönüllü ve istekli olma" ( $\mathrm{X}=3,40$ ve $\mathrm{S}=0,65$ ) maddeleri de yüksek değer alan maddeler arasında yer almıştır. Öne çıkan yedi başarılı çatışma yönetimi becerisinin tanımlayıcı istatistiklerine Tablo 11'de yer verilmiştir. 
Karabakkal H, Torun A.

Tablo 11. Başarılı çatışma yönetimi becerileri tanımlayıcı istatistikleri

\begin{tabular}{clcc}
\hline \multirow{2}{*}{ MADDE } & \multicolumn{1}{c}{$\begin{array}{c}\text { BAŞARILI ÇATIŞMA YÖNETIMİ BECERILERİ } \\
\text { TANIMLAYICI İSTATISTIKLERİ }\end{array}$} & $\mathrm{X}$ & $\mathrm{S}$ \\
\hline 1 & \multicolumn{1}{c}{ İletişime açık olma } & 3,57 & 0,53 \\
2 & Empati (önce anlamaya çalış, sonra anlaşılmayı bekle) & 3,54 & 0,58 \\
3 & Muhatabın ihtiyaçlarını ve kaygılarını anlamak için dinleme & 3,50 & 0,57 \\
4 & Çatışmayı tırmandıracak söz ve eylemlerden kaçınma & 3,48 & 0,68 \\
5 & Çatışmayı kişisel bir zafer kazanma gayesine taşımama & 3,46 & 0,71 \\
6 & Arkadan konuşmama, dedikoduya yer vermeme & 3,46 & 0,70 \\
7 & Çatışmayı çözme konusunda çaba sarf etmeye gönüllü ve istekli & 3,40 & 0,65 \\
\hline
\end{tabular}

$\mathrm{N}=133$, X: ortalama değer; en az 1, en çok 4 puan, S: standart sapma

\section{SONUÇ VE TARTIŞMA}

$\mathrm{Bu}$ çalışmanın amacı, kamu araştırma ve geliştirme merkezlerinde çalışanların iş yerinde şahit oldukları çatışma nedenlerini tespit etmek, etkili çatışma yönetimi becerileriyle ilgili görüşlerini ortaya koymak ve bu bulgulardan hareketle öncelikli öğrenme ve gelişim ihtiyaçlarını belirlemektir.

İş yerinde çatışmayı tetikleyen nedenlerle ilgili araştırma sonuçlarına göre, 'İletişim sırasında suçlayıcı bir dil kullanma" $(X=3,50$ ve $S=0,64)$ en çok dile getirilen çatışma nedeni olarak tespit edilmiştir. Araştırmalar; kişilerin muhakeme becerilerinin azaldığı ve savunmacı bir yaklaşıma bürünmeye meyilli oldukları durumlarda ilişkilerinde suçlayıcı bir dil kullandıklarını göstermektedir (Carnevale ve Probst, 1998; Hocker ve Wilmot, 1998). Bu bulguyu destekler nitelikte, anlaşmazlık durumlarında çalışanların olumsuz bir söylem geliştirdikleri, birbirlerine güven duygularının azaldığı, öfke ve hayal kırıklığı yaşadıkları görülmüştür (Jehn ve Mannix, 2001). Buradan hareketle, iletişimin suçlayıcı olduğu durumlarda işle ilgili tartışmalar, kişisel saldırılar olarak yorumlanabilmekte (De Clercq ve Belausteguigoitia, 2017); bu durum iş yerinde adaletsizlik algılarını beraberinde getirebilmekte (Jehn vd., 2008) ve de yapıcı iletişimin engellenmesinin de etkisiyle grup üyeleri arasındaki işbirliğine zarar verebilmektedir (Baron, 1991).

Çatışmayı tetikleyen nedenlerle ilgili olarak en çok öne çıkan diğer iki bulgu, "Dinleme hataları, muhatabı anlama gayesiyle dinlememe" $(X=3,41$ ve $S=0,69)$ ve "Kıskançlık ve öne çıkma isteği” ( $\mathrm{X}=3,41$ ve $\mathrm{S}=0,69)$ olmuştur. Uyuşmazlık sırasında taraflar çatışmanın kendileri için ne ifade ettiğini anlamaya çalışmaktadır (Isen, Labroo ve Durlach, 2004). Ne var ki anlaşmazlık durumlarında duygusal tepkiler, özellikle de öfke ve kıskançlık gibi duygular 
(Lazarus ve Lazarus, 1994) sıklıkla görülebilmekte; kişilerin birbirlerine sergiledikleri anlama çabası azalmaktadır (Amit ve Sagiv, 2013). Bu yönüyle araştırma bulguları literatürle paralellik göstermektedir.

Araştırmada çatışma nedenleriyle konusunda öne çıkan diğer iki bulgu da "Çalışanların görev tanımlarının yeterince net olmayışı" ( $\mathrm{X}=3,38$ ve $\mathrm{S}=0,73)$ ve "Kişiler arasındaki güven eksikliği” ( $\mathrm{X}=3,38$ ve $\mathrm{S}=0,69)$ olarak belirlenmiştir. Rekabetin çok, bütçe ve zamanın kısıtlı ve görevlerin/sorumlulukların belirsiz olduğu iş ortamlarının çatışmayı beraberinde getirdiği, araştırmalarda özellikle vurgulanan bir konudur (Aswathappa ve Ready, 2009; De Dreu ve Gelfand, 2008). Öte yandan, ilişkilerde güvensizlik duygusunun yaygın olduğu kültürlerde başkalarını ve sorunlarını önemseme duygusunun az olduğu görülmektedir (Kaushal ve Kwantes, 2006). Güven duygusunun olmadığı kurumlarda ise çalışanların önyargılı bilgi işleme ve kritik bilgileri saklama/paylaşmama gibi istenmeyen davranışlar sergiledikleri görülmüştür. Ancak iş yerinde belirsizlik az olduğunda ve çalışanlar arasında güven yüksek olduğunda ise çatışmaların azaldığı görülmüştür (Ayoko, 2016; Hempel, Zhang ve Tjosvold, 2008).

Araştırmada, çatışmaya neden olan etmenlerden birisi de "Kişilerin empati gösterme konusundaki eksiklikleri” ( $\mathrm{X}=3,36$ ve $\mathrm{S}=0,67$ ) şeklinde belirtilmiştir. Thomas ve Killman (1974), empati duygusu az olan kişilerin, başkaları pahasına kendi çıkarları doğrultusunda hareket edebildiklerini vurgulamıştır. Bu konuda Heider'in (1958) ve Campbell ve Sedikides'in (1999) bulgularından hareketle, özellikle Ar-Ge kurumu çalışanlarının olumlu benlik algılarını devam ettirme amacıyla kendine hizmet eden yanlılık ile istek ve ihtiyaçlarını merkeze alan algısal önyargıyı yaygın bir şekilde sergiledikleri düşünülmektedir. Bu durumun ise empatinin temeli olduğuna inanılan, anlamaya çalışma durumunu körelttiği ve salt anlaşılmayı bekleme durumunu arttırdı̆̆ 1 ileri sürülebilir.

Çatışmayı tetikleyen nedenler konusunda öne çıkan bir diğer etmen ise "Duyguların kontrolü ve etkin aktarımında karşılaşılan güçlükler” ( $\mathrm{X}=3,32$ ve $\mathrm{S}=0,67)$ olmuştur. Araştırmalar, olumsuz nitelikte ve etkin bir biçimde aktarılamayan duyguların iş yerinde düşmanca tutumlara neden olduğunu (Trudel ve Reio, 2011) ve çalışanlar arasındaki iyi niyet ve karşılıklı anlayışı olumsuz etkilediğini göstermiştir (Deutsch, 1969). Bu konuda karşılaşılan güçlüklerin yine çalışanların hedefe yönelik davranışlarını engellediği (Bruk-Lee ve Spector, 2012) ve aralarındaki takım ruhunu ve güveni de olumsuz etkilediği ortaya koyulmuştur (Jehn vd., 2008).

Ar-Ge kurumlarında başarılı çatışma yönetim becerileriyle ilgili araştırma sonuçlarına göre "İletişime açık olma" (X=3,57 ve $\mathrm{S}=0,53)$ en çok vurgulanan beceridir. İletişime açık 


\section{Karabakkal H, Torun A.}

olmanın ve açık iletişimin, çalışma gruplarında problemlerin saldırıya uğramışlık veya tehdit edilmişlik hissi oluşturmaksızın serbestçe tartışılmasına imkân sağladığı ve ekip ruhunu güçlendirdiği dile getirilmektedir (Jehn, 1997; Tekleab vd., 2009). Bundan dolayı bu becerinin geliştirilmesi kritik bir role rahiptir. Başarılı çatışma yönetimi konusunda öne çıkan bir diğer beceri ise "Empati duygusunun güçlendirilmesi" ( $X=3,54$ ve $S=0,58)$ olmuştur. Araştırmalar, empatinin çatışmanın tırmanmasının önüne geçtiğini ve sorunlara çözüm odaklı yaklaşma tutumlarını arttırdığını gösterdiğinden (Van Lissa vd., 2016), bu özelliğin güçlendirilmesi önem taşımaktadır.

İşlevsel çatışma yönetimi stratejileri konusunda öncelikli olarak belirtilen hususlardan birisi de "Muhatabın ihtiyaçlarını ve kaygılarını anlamak için dinleme" ( $X=3,50$ ve $S=0,57)$ olarak belirlenmiştir. Araştırmalar, güven duygusunun az olduğu belirsiz durumlarda kişilerin tartışma konularını kendilerine yapılmış bir saldırı gibi değerlendirme olasılıklarının yüksek olduğunu (Jehn, 1997) ve böyle durumlarda kişilerin uyuşmazlığın nedenlerini kapsamlı bir şekilde anlamak için çaba gösterme motivasyonlarının azaldığını (De Wit vd., 2013) göstermektedir. Öte yandan, belirsizlik oluşturan durumu aydınlatma çabası yüksek olan kişilerin daha fazla bilgi elde etme eğiliminde oldukları da görülmüştür (Van Hiel ve Mervielde, 2002). Araştırma sonucunda da ortaya koyulduğu üzere, etkili dinleme becerilerinin önemli bir işlevi olduğu anlaşılmaktadır.

"Çatışmayı tırmandıracak söz ve eylemlerden kaçınma” (X $=3,48$ ve $S=0,68)$ katılımcılar tarafından altı çizilen önemli bir beceri olmuştur. Basmakalıp (stereotypical) düşünceler, yeni bilgilerin anlaşılması ve işlenmesinde etkilidir (Bodenhausen, 1988) ve grup üyeleri arasında gerginlik ve bireysel kimliğe tehdit algısı oluşturabilmektedir (Jehn, 1995). Bu durum ise çatışmanın tırmanıp daha fazla kişiye yayılmasına; suçlama, hayal kırıklığı ve tahrik gibi işlevsiz duygusal tepkiler oluşmasına ve tarafların kişilikleriyle ilgili olumsuz değerlendirmelerin yapılmasına yol açtığından (Pruitt vd., 1997), bu konuyla ilgili becerilerin geliştirilmesi önemlidir ve üzerinde durulan husus bu araştırmada da öne çıkmıştır.

Araştırmada "Çatışmayı kişisel bir zafer kazanma gayesine taşımama" (X = 3,46 ve S $=0,71)$ ve "Arkadan konuşmama, dedikoduya yer vermeme" $(\mathrm{X}=3,46$ ve $\mathrm{S}=0,70)$ konusunda farkındalık kazandırılması da önemli birer strateji olarak ifade edilmiştir. Bunun gibi işlevsel becerilerin; çalışanların uyumunu ve samimiyetini güçlendireceği, iş yerindeki zorbalık davranışlarını azaltacağı, sorunların rahatlıkla ele alınmasını teşvik edeceği ve kişilerin duygu durumlarını rahatlıkla yansıtmalarına imkan vereceği belirtilmiştir (Baillien vd., 2009; Jehn, 1997; Schermerhorn vd., 2000). Dolayısıyla bu araştırmadaki bulgular da bu konuyu vurgular 
niteliktedir. Araştırmada öne çıkan son beceri ise "Çatışmayı çözme konusunda çaba sarf etmeye gönüllü ve istekli olma" ( $\mathrm{X}=3,40$ ve $\mathrm{S}=0,65)$ becerisidir. Özkalp, Sungur ve Özdemir'in (2009), çalışanların esneklik ve uyum sağlama kabiliyetlerinin ve çatışma yönetimi için çaba sarf etmeye istekli olma durumlarının, işlevsel çatışma yönetimi açısından önemini vurgulamaları da araştırmanın bu bulgusunu desteklemektedir.

Öte yandan, ülkemizde yapılan benzer akademik araştırmaların, örneklemini çoğunlukla devlet okullarındaki öğretmenlerin ve öğrencilerin oluşturduğu çalışmalardan meydana geldiği görülmektedir (Aydın, 2015; Polat, 2009; Sucuoğlu, 2015). Örneğin, Aydın (2015), çatışma durumlarını öğretmenler açısından ele aldığı araştırmasında, çatışmaya neden olan etmenlerin başında "öğretmenler ve okul müdürleri arasındaki algısal farklılıklar" ile "okul müdürlerinin yönetim tarzları ile öğretmenlerin yönetimden beklentilerindeki farkl1lıklar” gibi faktörlerin geldiğini belirtmiştir. Benzer şekilde Sucuoğlu (2015) da örneklemini öğretmenlerden oluşturduğu araştırmasında, iş bölümündeki adaletsizlikten kaynaklanan sorunların ve kişilerin birbirlerine karşı olumsuz tutumlarının, okullarda yaşanan yaygın çatışma durumları arasında bulunduğunu belirlemiştir. Polat (2009) ise öğrencilerin çatışmalarla etkin bir biçimde baş edebilmeleri için ihtiyaç duydukları becerilerin tespit edilmesini içeren çalışmasında, öğrenciler tarafindan en çok ihtiyaç duyulan becerilerin, "problem çözme becerileri”, "etkili karar verme becerileri” ve "etkin dinleme becerileri” olduğunu vurgulamıştır. Bu bulgular 1şığında, örneklemini Ar-Ge çalışanlarından teşkil eden mevcut çalışmanın, çatışmaya neden olan faktörler ile etkili çatışma yönetimi için ihtiyaç duyulan becerilerdeki farklılaşmayı ortaya koyması ve öğrenme ve gelişim alanlarına 1şık tutması açısından akademik yazına önemli katkılar sunduğuna inanılmaktadır.

Gelecekteki çalışmalar için araştırmacıların, işlevsel çatışma yönetimi becerileri konusunda özel sektör Ar-Ge merkezi çalışanlarının öğrenme ve gelişim ihtiyaçlarını inceleyerek bu çalışmanın bulgularıyla karşılaştırması önerilebilir. Ayrıca, bu konudaki ihtiyaçlar, kamu Ar-Ge merkezlerindeki yöneticiler düzeyinde de ele alınarak çalışanlar ve yöneticiler açısından kıyaslanabilir ve bulgular uygulamaya katkı sağlayabilir. Bunun yanında, bu araştırmanın bulgularından yola çıkılarak, işlevsel çatışma yönetimi becerilerini geliştirmek amacıyla öğrenme ve gelişim programları tasarlanıp uygulanabilir, etkileri araştırılarak katılımcıların elde edebileceği kazanımlar analiz edilebilir. Öte yandan, İK uygulayıcılarının, eğitim planlamaları sırasında araştırma bulgularından istifade edebilecekleri; eğiticilerin, öne çıkan sonuçları merkeze koyarak program tasarımı yapabilecekleri ve böylelikle ihtiyaca uygun eğitimler verebilecekleri umulmaktadır. Ar-Ge merkezi çalışan ve yöneticileri ise, araştırmanın 
bulgularından hareketle, çatışmaya neden olan etmenler ve etkili çatışma yönetimi konularında kendi özgün gelişim alanlarını belirleyerek farkındalıklarını arttırabilirler.

\section{KAYNAKÇA}

Amason, A. (1996). Distinguishing effects of functional and dysfunctional conflict on strategic decision making: Resolving a paradox for top management teams. Academy of Management Journal, 39, 123-148.

Amit, A., \& Sagiv, L. (2013). The role of epistemic motivation in individuals' response to decision complexity. Organizational Behavior and Human Decision Processes, 121(1), 104117.

Aswathappa, K., \& Reddy, G. (2009). Organisational Behavior (1st ed.). Mumbai (India): Himalaya Pub. House.

Aydın, B. (2015). Opinions of teachers and managers employed in schools regarding the causes and resolution of conflicts experienced in schools (The case of Karşıyaka) (Unpublished master thesis). Okan University, İstanbul, Turkey.

Ayoko, O. B., Härtel, C. E. J., \& Callan, V. J. (2002). Resolving the puzzle of productive and destructive conflict in culturally heterogeneous workgroups: A communication accommodation theory approach. International Journal of Conflict Management, 13(2), 165-195.

Baillien, E., Neyens, I., De Witte, H., \& De Cuyper, N. (2009). A qualitative study on the development of workplace bullying: Towards a three-way model. Journal of Community \& Applied Social Psychology, 19, 1-16.

Balkundi, P., \& Harrison, D. A. (2006). Ties, leaders, and time in teams: Strong inference about network structure's effects on team viability and performance. Academy of Management Journal, 49, 49 - 68.

Baron, R. A. (1991). Positive effects of conflict: A cognitive perspective. Employee Responsibilities and Rights Journal, 4(1), 25-36.

Bodenhausen, G. V. (1988). Stereotypic biases in social decision making and memory: Testing process models of stereotype use. Journal of Personality and Social Psychology, 55(5), 726737.

Bodtker, A. M., \& Katz Jameson, J. (2001). Emotion in conflict formation and its transformation: Application to organizational conflict management. International Journal of Conflict Management, 12(3), 259-275.

Bruk-Lee, V., \& Spector, P. E. (2012). Interpersonal conflict and stress at work. In A. Rossi, P. Perrewe, \& J. Meurs (Eds.), Coping and prevention (pp. 3-22). Charlotte, NC: Information Age Publishing.

Campbell, W. K., \& Sedikides, C. (1999). Self-threat magnifies the self-serving bias: A metaanalytic integration. Review of General Psychology, 3(1), 23-43.

Carnevale, P. J., \& Probst, T. M. (1998). Social values and social conflict in creative problem solving and categorization. Journal of Personality and Social Psychology, 74, 1300-1309. 
Cheong, J., \& Kim, C. (2017). Determinants of performance in government: Focusing on the effect of organizational politics and conflicts in organizations. International Journal of Public Administration, 1-13.

Coleman, P. T., \& Deutsch, M. (2000). Some guidelines for developing a creative approach to conflict. In M. Deutsch, \& P. T. Coleman (Eds.), The handbook of conflict resolution: Theory and practice (pp. 355- 365). San Francisco, CA: Jossey-Bass.

Curseu, P. L. (2006). Emergent states in virtual teams: A complex adaptive systems perspective. Journal of Information Technology, 21(4), 249-261.

De Clercq, D., \& Belausteguigoitia, I. (2017). Overcoming the dark side of task conflict: Buffering roles of transformational leadership, tenacity, and passion for work. European Management Journal, 35(1), 78-90.

De Dreu, C. K. W., \& Gelfand, M. J. (Eds.). (2008). The psychology of conflict and conflict management in organizations. New York, NY: Erlbaum.

De Dreu, C. K. W., \& Weingart, L. R. (2003). Task versus relationship conflict, team performance, and team member satisfaction: A meta-analysis. Journal of Applied Psychology, $88,741-749$.

De Wit, F. R. C., Jehn, K. A., \& Scheepers, D. (2013). Task conflict, information processing, and decision-making: The damaging effect of relationship conflict. Organizational Behavior and Human Decision Processes, 122(2), 177-189.

Demir, S. B., \& Bütüner, K. (2014). Sosyal bilgiler öğretmen adaylarının alan sınavına yönelik görüşlerinin incelenmesi. Mersin Üniversitesi Eğitim Fakültesi Dergisi, 10(2), 113-128.

Deutsch, M. (1969). Conflicts: Productive and destructive. Journal of Social Issues, 25, 7-41.

Dijkstra, M. T. M., De Dreu, C. K. W., Evers, A. \& Van Dierendonck, D. (2009). Passive responses to interpersonal conflict at work amplify employee strain. European Journal of Work and Organizational Psychology, 18(4), 405-423.

Fiske, S. T., \& Taylor, S. (1991). Social cognition. New York: McGraw-Hill.

Gayle, B. M., \& Preiss, R. W. (1998). Assessing emotionality in organizational conflicts. Management Communication Quarterly, 12(2), 280-302.

Gladstein, D. L. (1984). Groups in context: A model of task group effectiveness. Administrative Science Quarterly, 29(4), 449.

Guerra, J. M., Martínez, I., Munduate, L., \& Medina, F. J. (2005). A contingency perspective on the study of the consequences of conflict types: The role of organizational culture. European Journal of Work and Organizational Psychology, 14(2), 157-176.

Heider, F. (1958). The Psychology Of Interpersonal Relations. New York: Wiley.

Hempel, P.S., Zhang, Z.-X. \& Tjosvold, D. (2009), "Conflict management between and within teams for trusting relationships and performance in China", Journal of Organizational Behavior, 30(1), 41-65.

Hocker, J. L., \& Wilmot, W. W. (1998). Interpersonal conflict $\left(5^{\text {th }}\right.$ ed.). Madison, WI: Brown \& Benchmark. 
Isen, A. M., Labroo, A. A., \& Durlach, P. (2004). An influence of product and brand name on positive affect: Implicit and explicit measures. Motivation and Emotion, 28(1), 43-63.

Jehn, K. A. (1995). A multimethod examination of the benefits and detriments of intragroup conflict. Administrative Science Quarterly, 40(2), 256-282.

Jehn, K. A. (1997). A qualitative analysis of conflict types and dimensions in organizational groups. Administrative Science Quarterly, 42(3), 530-557.

Jehn, K. A., \& Bendersky, C. (2003). Intragroup conflict in organizations: A contingency perspective on the conflict-outcome relationship. Research in Organizational Behavior, 25, 187-242.

Jehn, K. A., \& Mannix, E. A. (2001). The dynamic nature of conflict: A longitudinal study of intragroup conflict and group performance. Academy of Management Journal, 44(2), 238-251.

Jehn, K. A., Greer, L., Levine, S., \& Szulanski, G. (2008). The effects of conflict types, dimensions, and emergent states on group outcomes. Group Decision and Negotiation, 17(6), 465-495.

Kaushal, R., \& Kwantes, C. T. (2006). The role of culture and personality in choice of conflict management strategy. International Journal of Intercultural Relations, 30(5), 579-603.

Lazarus, R. S., \& Lazarus, B. N. (1994). Passions And Reason: Making Sense Of Our Emotions. New York, NY: Oxford.

Marquis, B. L., \& Huston, J. C. (2000). Leadership roles and management functions in nursing. Philadelphia, PA: Lippincott, Williams \& Wilkins.

Marshall, C., \& Rossman, G. B. (2011). Designing qualitative research. Thousand Oaks, CA: Sage.

Meyer, S. (2004). Organizational response to conflict: Future conflict and work outcomes. Social Work Research, 3, 183-190.

Miles, M. B., \& Huberman, A. M. (1994). Qualitative Data Analysis (2 $2^{\text {nd }}$ ed.). Thousand Oaks, CA: Sage.

Nair, N. (2008). Towards understanding the role of emotions in conflict: A review and future directions. International Journal of Conflict Management, 19(4), 359-381.

Oore, D. G., Leiter, M. P., \& LeBlanc, D. E. (2015). Individual and organizational factors promoting successful responses to workplace conflict. Canadian Psychology, 56(3), 301.

Opatha, H. H. D. N. P. (2015). Organizational behavior. Colombo: Author Publication.

Özkalp, E., Sungur, Z., \& Özdemir, A.A. (2009). Conflict management styles of Turkish managers. Journal of European Industrial Training, 33(5), 419-438.

Patton, Q. M. (2014). Nitel araştırma ve değerlendirme yöntemleri. (M. Bütün ve S. B. Demir, Çev. Edt.). Ankara: Pegem Akademi.

Pelled, L. H. (1996). Demographic diversity, conflict, and work group outcomes: An intervening process theory. Organization Science, 7(6), 615-631. 
Polat, M. (2009). Conflict management and effective communication: types of conflict confronted and the skills, needs, and attitudes of students in handling conflicts. Unpublished master's thesis, Middle East Technical University, Ankara, Turkey.

Pruitt, D. G., Parker, J. C., \& Mikolic, J. M. (1997). Escalation as a reaction to persistent annoyance. International Journal of Conflict Management, 8(3), 252.

Rahim, A. M. (2001). Managing Conflict In Organizations ( $3^{\text {rd }}$ ed.). United States: Quorum Books, US.

Schaeffner, M., Huettermann, H., Gebert, D., Boerner, S., Kearney, E., \& Song, L. J. (2015). Swim or sink together: The potential of collective team identification and team member alignment for separating task and relationship conflicts. Group \& Organization Management, 40(4), 467-499.

Schermerhorn, J. R., Hunt, J. G., \& Osborn, R. N. (2000). Organizational behavior ( $7^{\text {th }}$ ed.). New York: John Wiley and Sons Inc.

Simons, T. L., \& Peterson, R. A. S. (2000). Task conflict and relationship conflict in top management teams: The pivotal role of intragroup trust. Journal of Applied Psychology, 85(1), $102-111$.

Sucuoğlu, E. (2015). Evaluation of the Conflict Causes and Conflict Management Approaches of the State Lycee Teachers. H. U. Journal of Education 30(4), 16-28.

Tekleab, A. G., Quigley, N. R., \& Tesluk, P. E. (2009). A longitudinal study of team conflict, conflict management, cohesion, and team effectiveness. Group \& Organization Management, 34(2), 170-205.

Thomas, K. W. \& Kilmann, R. H. (1974). Thomas-Kilmann Conflict Mode Instrument. Mountain View, CA: CPP, Inc

Trudel, J., \& Reio, T. G. (2011). Managing workplace incivility: The role of conflict management styles - antecedent or antidote? Human Resource Development Quarterly, 22(4), 395-423.

Van Hiel, A., \& Mervielde, I. (2002). Effects of ambiguity and need for closure on the acquisition of information. Social Cognition, 20(5), 380-408.

Van Lissa, C. J., Hawk, S. T., Branje, S., Koot, H. M., \& Meeus, W. H. J. (2016). Common and unique associations of adolescents' affective and cognitive empathy development with conflict behavior towards parents. Journal of Adolescence, 47, 60-70.

VERBI Software. (2018). MAXQDA 2018.02 Analytics Pro (Bilgisayar Program1). Berlin, Almanya: VERBI Yazılım. https://www.maxqda.com. 